\title{
Age and sex of surgeons and mortality of older surgical patients: observational study
}

\author{
Yusuke Tsugawa, ${ }^{1}$ Anupam B Jena, ${ }^{2,3,4}$ E John Orav, ${ }^{5,6}$ Daniel M Blumenthal, ${ }^{7}$ Thomas C Tsai, ${ }^{8,9}$ \\ Winta T Mehtsun, ${ }^{10}$ Ashish K Jha ${ }^{5,9,11}$
}

For numbered affiliations see end of article.

Correspondence to: Y Tsugawa ytsugawa@mednet.ucla.edu Additional material is published online only. To view please visit the journal online.

Cite this as: $B M J$ 2018;361:k1343 http://dx.doi.org/10.1136/bmj.k1343

Accepted: 7 March 2018

\section{ABSTRACT}

OBJECTIVE

To investigate whether patients' mortality differs according to the age and sex of surgeons.

DESIGN

Observational study.

SETTING

US acute care hospitals.

\section{PARTICIPANTS}

$100 \%$ of Medicare fee-for-service beneficiaries aged 65-99 years who underwent one of 20 major nonelective surgeries between 2011 and 2014.

\section{MAIN OUTCOME MEASURE}

Operative mortality rate of patients, defined as death during hospital admission or within 30 days of the operative procedure, after adjustment for patients' and surgeons' characteristics and indicator variables for hospitals.

RESULTS

892187 patients who were treated by 45826 surgeons were included. Patients' mortality was lower for older surgeons than for younger surgeons: the adjusted operative mortality rates were $6.6 \%(95 \%$ confidence interval $6.5 \%$ to $6.7 \%$ ), $6.5 \%$ (6.4\% to $6.6 \%), 6.4 \%$ (6.3\% to $6.5 \%$ ), and $6.3 \%$ (6.2\% to $6.5 \%$ ) for surgeons aged under 40 years, $40-49$ years, 50-59 years, and 60 years or over, respectively ( $P$ for trend $=0.001)$. There was no evidence that adjusted operative mortality differed between patients treated by female versus male surgeons (adjusted mortality $6.3 \%$ for female surgeons versus $6.5 \%$ for male surgeons; adjusted odds ratio $0.97,95 \%$ confidence interval 0.93 to 1.01). After stratification by sex of surgeon, patients' mortality declined with age of

\section{WHAT IS ALREADY KNOWN ON THIS TOPIC}

Surgical performance may improve over a surgeon's career from the accumulation of skills and experience but may decline owing to reductions in dexterity and outdated knowledge

Evidence is mixed as to whether older surgeons perform better or worse than younger surgeons

A recent study conducted in a single province in Canada suggested that female surgeons may have lower operative mortality than male surgeons

\section{WHAT THIS STUDY ADDS}

This study examined operative mortality of patients who underwent one of 20 major surgeries between 2011 and 2014 in the United States

Within the same hospital, patients treated by older surgeons had lower operative mortality compared with patients cared for by younger surgeons

No evidence was found that patients' mortality differed between male and female surgeons within the same hospital

surgeon for both male and female surgeons (except for female surgeons aged 60 or older); female surgeons in their 50 s had the lowest operative mortality.

\section{CONCLUSION}

Using national data on Medicare beneficiaries in the US, this study found that patients treated by older surgeons had lower mortality than patients treated by younger surgeons. There was no evidence that operative mortality differed between male and female surgeons.

\section{Introduction}

Despite strong interest in improving the quality of surgical care, the association between surgeons' characteristics-especially the age and sex of surgeons-and patients' outcomes has not been well understood. Some people assume that surgical performance will improve over the course of a surgeon's career through an accumulation of skills and experience, but others worry that a decline may occur at some point owing to deterioration of dexterity associated with aging or to changes in clinical management facilitated by evolving technology and new guidelines. ${ }^{1}{ }^{2}$ The relation between surgeon's age and surgical performance is an important health policy matter in light of the restriction in training hours for resident surgeons, because less experience during residency training can potentially lead to worse performance. For older surgeons, concerns about the quality of surgical care have led to debates about whether surgeons should have formal retirement ages. $^{34}$ Although some evidence suggests that older surgeons may have higher patient mortality than their younger peers, the data are old, both surgical training and surgical technology have changed substantially since these studies were conducted, and previous studies included elective surgeries, making it possible that older, more experienced surgeons treated more complicated patients. ${ }^{5-11}$

Less research has focused on how surgical outcomes differ between male and female surgeons. Previous studies on sex differences in patterns of clinical practice suggest that male and female surgeons may treat patients differently-most studies focused on patients undergoing breast cancer surgery and yielded mixed results as to whether process of care differs between male and female surgeons. ${ }^{12-15}$ However, less evidence exists on the association between surgeons' sex and patients' outcomes. A recent study conducted in Ontario, Canada, found that patients treated by female surgeons had slightly lower mortality overall but found no statistically significant differences in mortality for emergency surgery, a setting in which 
patients are less able to select their surgeon and confounding may be less of a problem. ${ }^{16}$ However, we lack any contemporary, national data comparing patients' outcomes according to age and sex of surgeons. Such empirical data would be useful in helping us to understand why some surgeons perform better than others do and what we might do to help surgeons improve outcomes.

In this context, using national data of Medicare beneficiaries in the US who underwent one of 20 major surgeries between 2011 and 2014, we examined whether surgeons' age and sex are associated with mortality rates in patients. We also analyzed whether the association between age of surgeon and patients' mortality varied between male and female surgeons and whether the association between surgeons' age/sex and patients' mortality varied by patients' illness severity.

\section{Methods}

Data

We linked the 100\% Medicare Inpatient and Carrier Files (2011-14) and a comprehensive physician database assembled by Doximity (described below). We restricted our sample to Medicare fee-for-service beneficiaries aged 65-99 years who underwent major surgical procedures. To minimize the bias caused by patients choosing their surgeon on the basis of surgeons' age or sex or by surgeons choosing their patients on the basis of illness severity, we focused on non-elective surgeries (emergency or urgent admissions and admissions from a trauma center identified using claim inpatient admission type code). We also restricted analysis to surgeries performed within three days of hospital admission. ${ }^{17-19}$ To allow for sufficient followup after surgery, we excluded patients who underwent procedures in December 2014.

We identified all patients who underwent one of 20 major surgical procedures. We selected 20 common surgical procedures: the 16 most common noncardiovascular surgeries in the Medicare population (hip and femur fracture, colorectal resection, cholecystectomy and common duct procedures, laminectomy, excision of peritoneal adhesions, fracture or dislocation of lower extremity other than hip or femur, lung resection, hysterectomy, amputation of lower extremity, nephrectomy, appendectomy, small bowel resection, pancreatic resection, gastrectomy, splenectomy, and esophageal resection) and four common cardiovascular surgeries examined in previous studies (carotid endarterectomy, heart valve procedures, coronary artery bypass grafting, and abdominal aortic aneurysm repair). ${ }^{112021}$ We identified these procedures by using Clinical Classification Software and Inpatient Quality Indicators developed by the Agency for Healthcare Research and Quality. ${ }^{22}$ A list of ICD-9 (international classification of disease, version 9) codes is available in supplementary table A.

\section{Identification of surgeons}

We identified the surgeon performing each procedure by using the unique provider identification number listed in the operating physician field of the inpatient claim, an approach validated in previous studies. ${ }^{11} 18$ 202123 We collected surgeons' characteristics by linking Medicare files to a comprehensive national physician database compiled by Doximity, a company that provides online professional networking services for US physicians. Doximity has assembled data on physicians' characteristics for both registered members of the service and non-registered physicians through multiple sources and data partnerships, including the National Plan and Provider Enumeration System, the National Provider Identifier Registry, the American Board of Medical Specialties, specialty societies, state licensing boards, and collaborating hospitals and medical schools. Using the Doximity database, we restricted our analysis to physicians designated as surgeons. Approximately 93\% (150 074/161 706) of physicians in our Medicare data could be linked to the Doximity database by using the physicians' unique identifiers. The Doximity database included information on surgeons' age, sex, specialty, medical school attended, and type of training (allopathic (MD) $V$ osteopathic (DO)). Previous studies have validated Doximity data for a random sample of physicians by using manual audits. ${ }^{24} 25$ More details about the Doximity database are described elsewhere. ${ }^{24-28}$

\section{Exposure variable}

The primary exposure variables were age and sex of surgeons. To allow for a non-linear relation between age of surgeon and patients' mortality, we categorized surgeons' age in 10 year increments for all analyses unless stated otherwise $(<40,40-49,50-59$, and $\geq 60$ years). Data on age and sex of surgeons were missing in our linked database for 3.1\% (1610/52 866) and $0.02 \%(12 / 52866)$, respectively, of surgeons. As the proportion of missing data was small, we assumed that missingness was unrelated to the variables involved in our analyses and did a complete case analysis (and assessed the effect of missing data in a sensitivity analysis).

\section{Outcome variables}

Our primary outcome was operative mortality, defined as death during hospital admission or within 30 days of the operative procedure, a commonly used measure of surgical quality used in previous studies. ${ }^{11} 202129$ Information on dates of death, including deaths out of hospital, was available in the Medicare Beneficiary Summary Files, in which more than 99\% (1010 018/1 010 527) have been verified using death certificates. ${ }^{30}$ We excluded patients whose death dates were not validated.

\section{Adjustment variables}

We adjusted for patients' characteristics, surgeons' characteristics, and hospital fixed effects. Patients' characteristics included age (as a continuous variable with quadratic and cubic terms to allow for a non-linear relation), sex, race or ethnic group (nonHispanic white, non-Hispanic black, Hispanic, other), 
procedure type (indicator variables for 20 surgeries), 27 comorbidities (Elixhauser comorbidity index ${ }^{31}$ ), median household income estimated from residential zip codes (with quadratic and cubic terms), an indicator for dual Medicaid coverage, and year and day of the week of surgery (because patients undergoing procedures during weekends may have higher mortality ${ }^{32-34}$ ). Surgeons' characteristics (other than age and sex) included specialty, the medical school from which a surgeon graduated (indicator variables for medical schools), credentials (whether surgeons underwent allopathic or osteopathic training), and annual operative volume (total number of selected Medicare surgeries performed per surgeon in our data; as a continuous variable with quadratic and cubic terms). Hospital fixed effects are indicator variables for hospitals (unique hospital identifiers) and account for both measured and unmeasured characteristics of hospitals, as long as they do not vary over time, including differences in patient populations, allowing us to effectively compare patients' mortality across surgeons of varying age or sex, within the same hospital. $^{35-37}$

\section{Statistical analysis}

Firstly, we investigated patients' and surgeons' characteristics according to surgeons' age and sex. Secondly, we examined the association between surgeons' age and operative mortality of patients by constructing multivariable logistic regression models adjusting for patients' characteristics, surgeons' characteristics, and hospital fixed effects. ${ }^{35-37}$ The unit of analysis was hospital admission, and standard errors were clustered at the surgeon level to account for potential correlation between patients treated by the same surgeon. After fitting regression models, we calculated adjusted patient mortality by estimating predicted probabilities of death for each patient fixing surgeons' age at each categorical level and averaging over our national sample, known as the marginal standardization form of predictive margins. ${ }^{38}$

Thirdly, we evaluated whether patients' mortality differs between male and female surgeons by using a similar method to that used for the analysis of surgeons' age. Fourthly, we analyzed whether the relation between surgeons' age and operative mortality varied between male and female surgeons. We regressed patients' mortality on the interaction between surgeons' age and sex, adjusting for patients' and surgeons' characteristics and hospital fixed effects. We used a Wald test adjusted for clustering (to approximate a likelihood ratio test because standard likelihood based tests are not available with clustered data) to formally test the interaction between surgeons' age and sex.

Finally, we did a stratified analysis by patients' illness severity, hypothesizing that the association would be strongest among patients at highest illness severity for whom differences in skill of the operating surgeon may matter most (whereas, for patients at low illness severity, the skill of the operating surgeon may have limited effect). To estimate illness severity for each patient, we regressed operative mortality on patients' characteristics and hospital fixed effects by using a logistic regression model. The predicted probabilities of operative mortality from this model represent illness severity and were used to stratify patients into three equal sized groups on the basis of illness severity. We then regressed patients' mortality on the interaction between surgeons' age/sex and the categories of illness severity, adjusting for patients' and surgeons' characteristics and hospital fixed effects. In this way, we could compare surgeons of different age/sex groups within each level of illness severity. To account for multiple comparisons, we considered a P value of less than 0.016 to be statistically significant.

\section{Secondary analyses}

We did several secondary analyses. Firstly, we evaluated whether the relation between surgeons' age/sex and patients' mortality varied by surgeons' operative volume. We classified surgeons into three groups with an equal number of surgeons on the basis of the total number of non-elective surgeries performed in our data and compared surgeons within each volume group by using a similar approach to the stratified analysis by patient illness severity. To account for multiple comparisons, we considered a $\mathrm{P}$ value of less than 0.016 to be statistically significant. Secondly, we evaluated the association between surgeons' age and operative mortality for individual surgeries. We compared surgeons for each procedure by using a similar approach to the stratified analysis by patient illness severity. To account for multiple comparisons, we considered a $\mathrm{P}$ value of less than 0.0025 to be statistically significant.

Thirdly, to evaluate whether the association between surgeons' age and operative mortality differs between elective and non-elective surgeries, we examined the association between surgeons' age and operative mortality among patients who underwent elective surgeries, instead of non-elective surgeries. Fourthly, female or older surgeons may perform fewer procedures and have worse patient outcomes, and adjustment for operative volume could offset the difference in mortality. To overcome this, we reanalyzed the data without adjustment for operative volume (but adjusted for all other variables). Fifthly, we tested whether our results held if we used surgeons' years of practice (years since completion of residency) instead of surgeons' age. We did not use years of practice in our main analyses because data were missing for $49 \%$ (23 169/47 688) of surgeons in our data.

Sixthly, to test the possibility that categorizing surgeons' age in 10 year increments is too crude, we examined the use of different model specifications for surgeon age: surgeons' age used as a continuous variable (linear assumption), surgeons' age used as a continuous variable with quadratic and cubic terms (cubic assumption), and surgeons' age used as continuous variable with linear splines (knots placed at age 40, 50, and 60). Finally, to investigate 
the possibility that missing data on surgeons' age may bias our estimates, we built a weighted regression model in which weights were generated on the basis of the inverse probability of surgeons' age data being observed. ${ }^{39}$ We used SAS version 9.4 for data preparation and Stata version 14 for analyses.

\section{Patient involvement}

No patients were involved in setting the research question or the outcome measures, nor were they involved in developing plans for the design or implementation of the study. No patients were asked to advise on interpretation or writing up of results. There are no plans to disseminate the results of the research to study participants or the relevant patient community. Patient consent was not required for the study.

\section{Results}

\section{Characteristics of surgeons and patients}

Our sample included 45826 surgeons with a mean age of 50.5 years and a median age of 50.0 years. Within the same hospital (adjusted for hospital fixed effects), older surgeons were more likely to be male (3.1\% of surgeons aged $\geq 60$ years were female; $20.1 \%$ of surgeons aged $<40$ years were female) and to have graduated from allopathic medical schools (table 1). Patients treated by older surgeons were slightly younger, were less likely to be female, had slightly lower income, were less likely to have congestive heart failure and mental illness, and were more likely to have diabetes.

Overall, $10.1 \%$ (4634/45 826) of surgeons were female. Within the same hospital, female surgeons were younger (43.0 $\mathrm{V} 49.3$ years; distribution of surgeons' age by sex is shown in supplementary figure A) and performed smaller numbers of procedures (39.9 v 72.9) (table 2). Patients of female surgeons were slightly younger (77.6 $v 78.8$ years) and more likely to have cancer but were less likely to have chronic obstructive pulmonary disease, diabetes, or renal failure.

\section{Surgeons' age and operative mortality}

The overall operative mortality in our final sample of 892187 surgeries was $6.4 \%(n=56803)$. After adjustment for potential confounders, operative mortality was lower for older surgeons than younger surgeons (table 3). The relation between surgeons' age and patients' mortality was monotonic and linear; the adjusted operative mortality rates were $6.6 \%$ (95\% confidence interval $6.5 \%$ to $6.7 \%), 6.5 \%(6.4 \%$ to $6.6 \%), 6.4 \%$ (6.3\% to $6.5 \%$ ), and $6.3 \%$ (6.2\% to $6.5 \%)$ for surgeons aged under 40, 40-49, 50-59, and 60 or over, respectively ( $\mathrm{P}$ for trend $=0.001$ ).

\begin{tabular}{|c|c|c|c|c|}
\hline \multirow[b]{2}{*}{ Characteristics } & \multicolumn{4}{|c|}{ Surgeon's age, years } \\
\hline & $<40(n=10193)$ & $40-49(n=17087)$ & $50-59(n=16144)$ & $\geq 60(n=10972)$ \\
\hline \multicolumn{5}{|l|}{ Surgeons } \\
\hline Mean age, years & 35.8 & 44.4 & 54.3 & 65.1 \\
\hline Female sex & $2050(20.1)$ & $2238(13.1)$ & $1066(6.6)$ & $340(3.1)$ \\
\hline \multicolumn{5}{|l|}{ Credentials: } \\
\hline MD & $9852(96.7)$ & $16477(96.4)$ & $15781(97.8)$ & $10859(99.0)$ \\
\hline DO & $341(3.4)$ & $610(3.6)$ & $363(2.3)$ & $113(1.0)$ \\
\hline No of non-elective surgeries* & 61.6 & 71.8 & 73.7 & 64.2 \\
\hline \multicolumn{5}{|l|}{ Patients } \\
\hline No of Medicare surgeries in 2011-14 & 149349 & 292103 & 283007 & 167728 \\
\hline Mean age, years & 79.6 & 78.7 & 78.4 & 78.5 \\
\hline Female sex & $99242(66.5)$ & $181571(62.2)$ & $170314(60.2)$ & $100486(59.9)$ \\
\hline \multicolumn{5}{|l|}{ Race/ethnicity: } \\
\hline White & $130636(87.5)$ & $255064(87.3)$ & $247546(87.5)$ & $146477(87.3)$ \\
\hline Black & $8154(5.5)$ & $15949(5.5)$ & $15056(5.3)$ & $9292(5.5)$ \\
\hline Hispanic & $6362(4.3)$ & $12648(4.3)$ & $12198(4.3)$ & $7246(4.3)$ \\
\hline Others & $4197(2.8)$ & $8442(2.9)$ & $8207(2.9)$ & $4713(2.8)$ \\
\hline Median household income, \$ & 56666 & 56575 & 56627 & 56405 \\
\hline Medicaid status & $26883(18.0)$ & $49365(16.9)$ & $46130(16.3)$ & $27340(16.3)$ \\
\hline \multicolumn{5}{|l|}{ Coexisting conditions: } \\
\hline Congestive heart failure & $21193(14.2)$ & $37097(12.7)$ & $34244(12.1)$ & $20295(12.1)$ \\
\hline Chronic obstructive pulmonary disease & $29392(19.7)$ & $57866(19.8)$ & $56432(19.9)$ & $33093(19.7)$ \\
\hline Diabetes & $37278(25.0)$ & $74720(25.6)$ & $73582(26.0)$ & $43878(26.2)$ \\
\hline Renal failure & $22104(14.8)$ & $42355(14.5)$ & $40725(14.4)$ & $24488(14.6)$ \\
\hline Neurological disorders & $19983(13.4)$ & $35257(12.1)$ & $32234(11.4)$ & $19456(11.6)$ \\
\hline Cancer & $8214(5.5)$ & $16650(5.7)$ & $15848(5.6)$ & $9393(5.6)$ \\
\hline Mental illness & $20461(13.7)$ & 36805 (12.6) & $34244(12.1)$ & $19624(11.7)$ \\
\hline \multicolumn{5}{|c|}{$\begin{array}{l}\text { Adjusted for hospital where patient was treated by using hospital fixed effects and estimating marginal effects. } \\
\text { Linear probability models were used for binary variables. Differences were } P<0.001 \text { except for race/ethnicity }(P=0.42 \text { for white, } P=0.08 \text { for black, } P=0.80 \\
\text { for Hispanic, and } P=0.19 \text { for others), household income }(P=0.004) \text {, chronic obstructive pulmonary disease }(P=0.25) \text {, renal failure }(P=0.04) \text {, and cancer } \\
(P=0.29) \text {. } \\
\text { *Estimated number of non-elective surgeries per surgeon in } 2011-14 \text {, based on assumption that proportion of Medicare beneficiaries with Medicare } \\
\text { Advantage is } 30 \% \text { and that Medicare beneficiaries comprise approximately } 34 \% \text { of all surgeries in US. }{ }^{40}\end{array}$} \\
\hline
\end{tabular}




\begin{tabular}{|c|c|c|}
\hline \multirow[b]{2}{*}{ Characteristics } & \multicolumn{2}{|l|}{ Surgeon's sex } \\
\hline & Male $(n=41192)$ & Female $(n=4634)$ \\
\hline \multicolumn{3}{|l|}{ Surgeons } \\
\hline Mean age, years & 49.3 & 43.0 \\
\hline \multicolumn{3}{|l|}{ Credentials: } \\
\hline$M D$ & $40109(97.4)$ & $4478(96.6)$ \\
\hline DO & $1083(2.6)$ & $156(3.4)$ \\
\hline No of non-elective surgeries* & 85.7 & 47.0 \\
\hline \multicolumn{3}{|l|}{ Patients } \\
\hline No of Medicare surgeries in 2011-14 & 840402 & 51785 \\
\hline Mean age, years & 78.8 & 77.6 \\
\hline Female sex & $519537(61.8)$ & $32091(62.0)$ \\
\hline \multicolumn{3}{|l|}{ Race/ethnicity: } \\
\hline White & $735604(87.5)$ & $44147(85.3)$ \\
\hline Black & $45046(5.4)$ & $3361(6.5)$ \\
\hline Hispanic & $35801(4.3)$ & $2593(5.0)$ \\
\hline Others & $23951(2.9)$ & $1684(3.3)$ \\
\hline Median household income, $\$$ & 56586 & 56395 \\
\hline Medicaid status & $141019(16.8)$ & $8783(17.0)$ \\
\hline \multicolumn{3}{|l|}{ Coexisting conditions: } \\
\hline Congestive heart failure & $106395(12.7)$ & $6504(12.6)$ \\
\hline Chronic obstructive pulmonary disease & $166820(19.9)$ & $9958(19.2)$ \\
\hline Diabetes & $216740(25.8)$ & $12755(24.6)$ \\
\hline Renal failure & $123035(14.6)$ & $6753(13.0)$ \\
\hline Neurological disorders & $101857(12.1)$ & $5277(10.2)$ \\
\hline Cancer & $46558(5.5)$ & $3495(6.8)$ \\
\hline Mental illness & $105386(12.5)$ & $5660(10.9)$ \\
\hline \multicolumn{3}{|c|}{$\begin{array}{l}\text { Adjusted for hospital where patient was treated by using hospital fixed effects and estimating marginal effects. } \\
\text { Linear probability models were used for binary variables. Differences were } P<0.001 \text { except for surgeons' } \\
\text { credentials }(P=0.15) \text {, patients' sex }(P=0.69) \text {, household income }(P=0.051) \text {, Medicaid status ( } P=0.34) \text {, } \\
\text { congestive heart failure ( } P=0.56) \text {, and chronic obstructive pulmonary disease }(P=0.001) \text {. } \\
\text { *Estimated number of non-elective surgeries per surgeon in } 2011 \text {-14, based on assumption that proportion } \\
\text { of Medicare beneficiaries with Medicare Advantage is } 30 \% \text { and that Medicare beneficiaries comprise } \\
\text { approximately } 34 \% \text { of all surgeries in US. }{ }^{40}\end{array}$} \\
\hline
\end{tabular}

\section{Surgeons' sex and operative mortality}

After adjusting for potential confounders, we found no evidence that operative mortality differed between female and male surgeons (adjusted operative mortality $6.3 \%$ for female surgeons versus $6.5 \%$ for male surgeons; adjusted odds ratio 0.97, 95\% confidence interval 0.93 to $1.01 ; \mathrm{P}=0.14$ ) (table 3 ). The associations between other characteristics of surgeons and operative mortality are shown in supplementary table B.

\section{Interaction between surgeons' age and sex}

The number of deaths in the patient population categorized by age and sex of surgeons is shown in supplementary table $\mathrm{C}$. We found that the operative mortality of older surgeons was lower than that of younger surgeons for both male and female surgeons (except for female surgeons aged 60 or older), with female surgeons aged 50-59 years having the lowest operative mortality across all groups (fig 1 and supplementary table D). The formal test of interaction between surgeons' age and sex was statistically significant $(\mathrm{P}=0.03)$.

\section{Surgeons' age/sex and operative mortality, by patients' illness severity}

We found that operative mortality was lower for older surgeons than younger surgeons treating patients at high risk but not for those at low or medium risk, after Bonferroni adjustment (table 4). The formal test of interaction was not significant $(\mathrm{P}=0.78)$. Operative mortality did not differ between male and female surgeons by patients' illness severity, after Bonferroni adjustment (table 5). The formal test of interaction between surgeons' sex and patients' illness severity was not statistically significant $(\mathrm{P}=0.09)$.

\section{Secondary analyses}

Older surgeons had lower operative mortality than younger surgeons among high volume surgeons; however, we did not observe a systematic relation between surgeons' age and operative mortality for low and medium volume surgeons (supplementary table E). The formal test of interaction was not statistically significant $(\mathrm{P}=0.73)$. The relation between surgeons' sex and operative volume did not vary by operative volume ( $\mathrm{P}$ for interaction=0.13) (supplementary table $\mathrm{F}$ ).

Operative mortality was lower for older surgeons for many procedures, although differences were not statistically significant for most procedures owing to small sample sizes (supplementary table G). The interaction between surgeons' age and procedure type was statistically significant $(\mathrm{P}=0.002)$. We found no evidence that adjusted operative mortality differed between male and female surgeons for individual procedures (supplementary table $\mathrm{H}$ ), and the interaction between surgeons' sex and procedure type was not statistically significant $(\mathrm{P}=0.66)$.

We found no evidence that operative mortality differed between younger and older surgeons or between male and female surgeons for elective surgeries (supplementary table I). The association between surgeons' age/sex and operative mortality was unaffected by removal of operative volume from

\begin{tabular}{|c|c|c|c|c|c|}
\hline & No of surgeries (No of surgeons) & $\begin{array}{l}\text { Crude operative } \\
\text { mortality, \% }(95 \% \mathrm{Cl})\end{array}$ & $\begin{array}{l}\text { Adjusted operative } \\
\text { mortality*, } \%(95 \% \mathrm{Cl})\end{array}$ & $\begin{array}{l}\text { Adjusted odds } \\
\text { ratio* }(95 \% \mathrm{Cl})\end{array}$ & $P$ value \\
\hline \multicolumn{6}{|c|}{ Surgeons' age, years } \\
\hline$<40$ & $149349(10193)$ & $6.7(6.6$ to 6.9$)$ & $6.6(6.5$ to 6.7$)$ & Reference & \\
\hline $40-49$ & $292103(17087)$ & $6.6(6.5$ to 6.6$)$ & $6.5(6.4$ to 6.6$)$ & $0.98(0.96$ to 1.01$)$ & 0.25 \\
\hline $50-59$ & 283007 (16144) & $6.3(6.2$ to 6.4$)$ & $6.4(6.3$ to 6.5$)$ & 0.97 (0.94 to 0.99$)$ & 0.02 \\
\hline$\geq 60$ & $167728(10972)$ & $6.4(6.3$ to 6.5$)$ & $6.3(6.2$ to 6.5$)$ & $0.95(0.92$ to 0.99$)$ & 0.005 \\
\hline \multicolumn{6}{|c|}{ Surgeons' sex } \\
\hline Male & $840402(41192)$ & $6.5(6.4$ to 6.5$)$ & $6.5(6.4$ to 6.5$)$ & Reference & \\
\hline Female & $51785(4634)$ & 6.8 (6.6 to 7.0$)$ & $6.3(6.1$ to 6.5$)$ & 0.97 (0.93 to 1.01$)$ & 0.14 \\
\hline
\end{tabular}




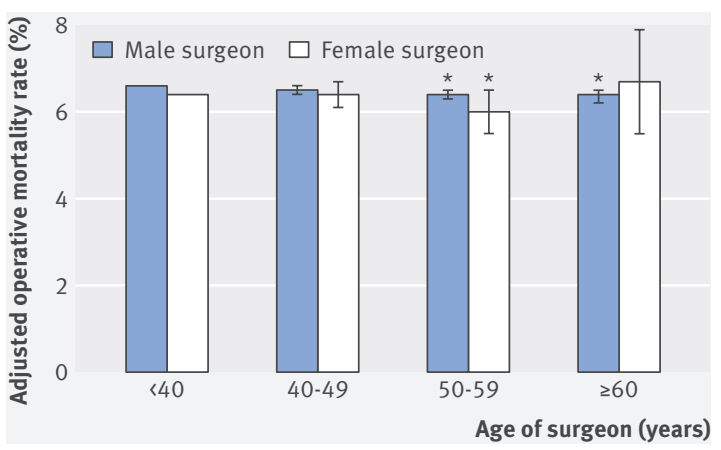

Fig 1 | Adjusted operative mortality of patients: interaction between age and sex of surgeons. Error bars represent $95 \% \mathrm{Cls}$ of estimates. Interaction between surgeons' age and sex was statistically significant $(P=0.03)$. *Statistically significant difference compared with surgeons aged $<40$ years for given sex

the regression model (supplementary table J), by use of years since completion of residency instead of surgeons' age (supplementary table K), by use of different model specifications for surgeons' age (supplementary table L and supplementary figure $\mathrm{B}$, showing the results of a linear spline model), or after accounting for missing data on surgeons' age by using inverse probability weights (supplementary table M).

\section{Discussion}

Using a national sample of Medicare patients who underwent surgeries in US hospitals during 2011-14, we found that operative mortality was lower for older surgeons than for younger surgeons but that patients' mortality did not differ meaningfully between male and female surgeons. When we stratified by surgeons' sex, we found that patients' mortality declined with surgeons' age for both male and female surgeons (except for female surgeons aged 60 or older), with female surgeons in their 50s having the lowest operative mortality. These findings are different from our previous analyses of general internists-female internists and younger internists had lower patient mortality ${ }^{26}{ }^{41}$ which may shed light on the relative importance of knowledge versus procedural skills in medical versus surgical fields. Taken together, these findings provide evidence of a long "learning curve" in surgical practice that has a potentially meaningful effect on patients' outcomes, as well as that male and female surgeons generally deliver care of equivalent quality.

\begin{tabular}{|c|c|c|c|c|c|}
\hline \multirow{2}{*}{$\begin{array}{l}\text { Patients' } \\
\text { illness severity }\end{array}$} & \multicolumn{4}{|c|}{ Surgeons' age, years } & \multirow{2}{*}{$\begin{array}{l}\mathrm{P} \text { for } \\
\text { trend }\end{array}$} \\
\hline & $<40$ & $40-49$ & $50-59$ & $\geq 60$ & \\
\hline Low & 3.7 (3.3 to 4.1$)$ & 3.6 (3.3 to 3.8$)$ & 3.6 (3.3 to 3.8$)$ & 3.7 (3.4 to 4.0$)$ & 0.90 \\
\hline Medium & $6.0(5.7$ to 6.2$)$ & $5.8(5.6$ to 6.0$)$ & $5.6(5.5$ to 5.8$)$ & $5.6(5.4$ to 5.9$)$ & 0.02 \\
\hline High & $7.3(7.1$ to 7.5$)$ & $7.2(7.1$ to 7.4$)$ & $7.1(7.0$ to 7.3$)$ & $7.0(6.9$ to 7.2$)$ & 0.01 \\
\hline
\end{tabular}

\begin{tabular}{|c|c|c|c|}
\hline \multicolumn{4}{|c|}{$\begin{array}{l}\text { Table } 5 \text { | Adjusted operative mortality of patien } \\
\text { surgeons' sex and patients' illness severity. Va } \\
\text { percentages }(95 \% \mathrm{Cl}) \text { unless stated otherwise }\end{array}$} \\
\hline \multirow{2}{*}{$\begin{array}{l}\text { Patients' illness } \\
\text { severity }\end{array}$} & \multicolumn{2}{|c|}{ Surgeons' sex } & \multirow[b]{2}{*}{$P$ value } \\
\hline & Male & Female & \\
\hline Low & $3.6(3.5$ to 3.8$)$ & $3.2(2.7$ to 3.6$)$ & 0.07 \\
\hline Medium & $5.8(5.7$ to 5.9$)$ & $5.3(4.9$ to 5.7$)$ & 0.03 \\
\hline High & $7.2(7.1$ to 7.3$)$ & $7.1(6.8$ to 7.4$)$ & 0.67 \\
\hline \multicolumn{4}{|c|}{$\begin{array}{l}\text { Adjusted for patients' characteristics, surgeons' characteristics, and } \\
\text { hospital fixed effects. Standard errors were clustered at surgeon level. } \\
\text { P value of }<0.016 \text { was considered statistically significant. Interaction } \\
\text { between surgeons' sex and patients' illness severity was not statistically } \\
\text { significant }(P=0.09) \text {. }\end{array}$} \\
\hline
\end{tabular}

\section{Possible explanations for and implications of findings}

Several mechanisms may explain the observed association between surgeons' age and patients' mortality. Firstly, the accumulation of skills and knowledge from experience may lead to better surgical performance. We found the strongest association between surgeons' age and operative mortality among surgeons with high and medium operative volumes, suggesting that surgeons with sufficient operative volume accumulate the skills and experience needed to improve surgical performance over the course of their careers (on the contrary, surgical performance may deteriorate for older surgeons if they perform only a small number of procedures). Secondly, our findings could be due, at least in part, to changes in the structure and nature of surgical residency training following changes in duty hour regulations for trainee physicians. ${ }^{42} 43$ Although a previous study found that duty hour regulations did not affect the quality of care provided by surgeons, ${ }^{44}$ the study focused only on outcomes of surgeons during residency and did not evaluate their independent practice after residency. It is still possible that our findings could be explained by a "cohort effect" in which recent duty hour regulations have had a long term effect on the performance of younger surgeons represented in our data. Finally, these findings may be explained by self selection of surgeons to continue (or quit) performing surgical procedures. Older surgeons who continue to perform procedures throughout their career may be those who are highly skilled, whereas lower skilled surgeons may decide to refrain from procedures and focus on administrative work, research, or teaching as they age.

Although the difference in operative mortality between younger and older surgeons was modest, a $5 \%$ difference in odds of mortality between surgeons aged under 40 years and those aged 60 years or over is a clinically meaningful difference. These results, if causal, suggest that for every 333 Medicare beneficiaries who undergo surgery in the US, one fewer death would occur if surgical quality of care was equivalent between younger and older surgeons. The population level effect would be larger if these findings were found to apply equally to non-Medicare populations.

Our work also adds to the growing literature on sex differences in workplace experiences and work 
performance of surgeons. Previous work has shown that, compared with male surgeons, female surgeons are compensated less and are less likely to be full professors in US medical schools. ${ }^{24}$ 25 45-50 The sex difference in salary tends to be larger among surgical sub-specialties compared with medical specialties. ${ }^{25} 45$ Moreover, despite substantial increases over the past decade in the proportion of US surgical trainees who are women, the proportion of women who are full professors in surgery has remained stagnant. ${ }^{49}$ Our findings suggest that male and female surgeons deliver clinical work of equal quality-at least in terms of operative mortality-and reinforce the need to ensure that female surgeons are rewarded equally for their work.

\section{Limitations of study}

Our study has limitations. Firstly, as with any observational study, we could not fully account for unmeasured confounders. Older surgeons may be more selective about the patients on whom they operate and may be less likely to operate on patients at high risk. However, patients' characteristics, including predicted mortality, were similar across surgeons' age groups. Alternatively, if more experienced older surgeons tend to operate on patients with higher complexity, our estimates would be biased toward the null. Secondly, coding practices may differ between younger and older surgeons, which may lead to inaccurate risk adjustment in our models. However, this potential limitation is less concerning given that we compared younger and older surgeons within the same hospital, in which coding patterns are plausibly more homogeneous. Thirdly, our outcomes were limited to operative mortality and may not be generalizable to other clinical outcomes (for example, long term mortality, patients' experience, or complication rates) or to measures of resource use. Lastly, our analysis was limited to Medicare patients treated by surgeons; therefore, our findings may not be generalizable to non-Medicare populations, physicians from other specialties, or outpatient care.

\section{Strengths and limitations in relation to other studies}

Contrary to our findings, previous studies have suggested worsening patient outcomes or complication

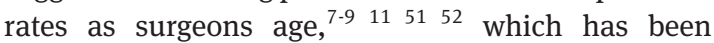
interpreted as a decline in dexterity, visual acuity, and cognitive functioning due to aging. ${ }^{124}$ However, we are aware of only one study that used nationally representative data to examine the relation between surgeons' age and operative mortality across a broad range of procedures. Waljee and colleagues examined Medicare beneficiaries who underwent one of eight procedures in 1998-99 and reported that operative mortality was higher for older surgeons. ${ }^{11}$ There are several reasons why our findings may differ from this previous work. Firstly, the previous study had limited data on surgeons' characteristics, which may have led to confounding by unmeasured variables. Specifically, differences in outcomes that were posited to be a consequence of surgeons' age might actually have been due to other characteristics of surgeons that correlate with age. ${ }^{5-11}$ We countered this potential confounding by adjusting for several characteristics of surgeons, including sex and medical school attended, which were not adjusted for in previous studies. Secondly, they evaluated operations performed by surgeons who had completed surgical training more than 15 years before the surgeons included in our study. Surgical training and practice have changed substantially since the previous study was performed, and the findings may not generalize to contemporary surgical practice. In addition to substantial advances in surgical technologies, changes in surgical residency training and duty hour requirements may have influenced the contemporary relation between surgeons' age and patients' outcomes. ${ }^{44-55}$ Finally, the previous study included both elective and non-elective surgeries, which would increase the likelihood of confounding by patient selection if more complicated cases are assigned to more experienced older surgeons rather than to younger surgeons. Our secondary analysis, which found no relation between surgeons' age and operative mortality among elective surgeries, supports the plausibility of this hypothesis.

We are not aware of previous studies that have used national data to examine the association between surgeons' sex and patients' outcomes. A recent study conducted in Ontario, Canada, found that patients treated by female surgeons were less likely to die overall, but patients' mortality did not differ between male and female surgeons for emergency surgery-for which patients are less likely to select their surgeonwhich is consistent with our findings. ${ }^{16} \mathrm{~A}$ few studies, most of which focused on patients undergoing breast cancer surgery, examined differences in clinical practices and processes of care, as opposed to surgical outcomes, and found mixed results. ${ }^{12-15}$

\section{Conclusions}

Using national data of Medicare beneficiaries who underwent surgical procedures in the US, we found that older surgeons had modestly lower operative compared with younger surgeons, whereas no evidence existed of an association between surgeons' sex and operative mortality. Our finding that younger surgeons have higher mortality suggests that more oversight and supervision early in surgeons' post-residency career may be useful and warrants further empiric investigation. Equivalent outcomes between male and female surgeons suggest that patients undergoing surgery receive high quality care irrespective of the sex of the surgeon.

\section{AUTHOR AFFILIATIONS}

${ }^{1}$ Division of General Internal Medicine and Health Services Research, David Geffen School of Medicine at UCLA, Los Angeles, CA, USA

${ }^{2}$ Department of Health Care Policy, Harvard Medical School, Boston, MA, USA

${ }^{3}$ Department of Medicine, Massachusetts General Hospital, Boston, MA, USA 
${ }^{4}$ National Bureau of Economic Research, Cambridge, MA, USA ${ }^{5}$ Division of General Internal Medicine and Primary Care, Brigham and Women's Hospital, Boston, MA, USA

${ }^{6}$ Department of Biostatistics, Harvard T.H. Chan School of Public Health, Boston, MA, USA

${ }^{7}$ Division of Cardiology, Massachusetts General Hospital, Boston, MA, USA

${ }^{8}$ Department of Surgery, Brigham and Women's Hospital, Boston, MA, USA

${ }^{9}$ Department of Health Policy and Management, Harvard T.H. Chan School of Public Health, Boston, MA, USA

${ }^{10}$ Division of Surgery, Massachusetts General Hospital, Boston, MA, USA

${ }^{11}$ The VA Healthcare System, Boston, MA 02138, USA

Contributors: All authors contributed to the design and conduct of the study, data collection and management, and analysis and interpretation of the data; and preparation, review, or approval of the manuscript. YT is the guarantor.

Funding: ABJ was supported by the Office of the Director, National Institutes of Health (NIH early independence award, grant 1DP50D017897). Study sponsors were not involved in study design, data interpretation, writing, or the decision to submit the article for publication

Competing interests: All authors have completed the ICMJE uniform disclosure form at www.icmje.org/coi_disclosure.pdf (available on request from the corresponding author) and declare: no support from any organization for the submitted work, other than that detailed above; $\mathrm{AB}$ ) has received consulting fees unrelated to this work from Pfizer, Hill Rom Services, Bristol Myers Squibb, Novartis Pharmaceuticals, Vertex Pharmaceuticals, and Precision Health Economics, a company providing consulting services to the life sciences industry;no other relationships or activities that could appear to have influenced the submitted work.

Ethical approval: The study was approved by the institutional review board at Harvard Medical School.

Data sharing: No additional data available.

Transparency statement: The corresponding author affirms that the manuscript is an honest, accurate, and transparent account of the study being reported; that no important aspects of the study have been omitted; and that any discrepancies from the study as planned (and, if relevant, registered) have been explained.

This is an Open Access article distributed in accordance with the Creative Commons Attribution Non Commercial (CC BY-NC 4.0) license, which permits others to distribute, remix, adapt, build upon this work non-commercially, and license their derivative works on different terms, provided the original work is properly cited and the use is non-commercial. See: http://creativecommons.org/licenses/ by-nc/4.0/.

1 Katlic MR, Coleman J. The aging surgeon. Ann Surg 2014;260: 199-201. doi:10.1097/SLA.0000000000000667

2 Waljee JF, Greenfield LI. Aging and surgeon performance. Adv Surg 2007:41:189-98. doi:10.1016/j.yasu.2007.05.012

3 American College of Surgeons Board of Governors Physician Competency and Health Workgroup. Statement on the aging surgeon. Bull Am Coll Surg 2016:101:42-3.

4 Bhatt NR, Morris M, O'Neil A, Gillis A, Ridgway PF. When should surgeons retire?Br / Surg 2016;103:35-42. doi:10.1002/bjs.9925

5 Bilimoria KY, Phillips JD, Rock CE, Hayman A, Prystowsky JB, Bentrem DJ. Effect of surgeon training, specialization, and experience on outcomes for cancer surgery: a systematic review of the literature. Ann Surg Oncol 2009:16:1799-808. doi:10.1245/s10434-0090467-8

6 Chai CY, Chen CH, Lin HW, Lin HC. Association of increasing surgeon age with decreasing in-hospital mortality after coronary artery bypass graft surgery. World / Surg 2010;34:3-9. doi:10.1007/s00268-0090291-0

7 Hartz AJ, Kuhn EM, Pulido J. Prestige of training programs and experience of bypass surgeons as factors in adjusted patient mortality rates. Med Care 1999;37:93-103. doi:10.1097/ 00005650-199901000-00013

8 Norcini IJ, Boulet IR, Opalek A, Dauphinee WD. Outcomes of cardiac surgery: associations with physician characteristics, institutional characteristics, and transfers of care. Med Care 2013;51:1034-9. doi:10.1097/MLR.0b013e3182a048af

9 O’Neill L, Lanska DJ, Hartz A. Surgeon characteristics associated with mortality and morbidity following carotid endarterectomy. Neurology 2000;55:773-81. doi:10.1212/WNL.55.6.773
10 Prystowsky JB. Are young surgeons competent to perform alimentary tract surgery?Arch Surg 2005;140:495-500, discussion 500-2. doi:10.1001/archsurg.140.5.495

11 Waljee JF, Greenfield LJ, Dimick JB, Birkmeyer JD. Surgeon age and operative mortality in the United States. Ann Surg 2006;244: 353-62.

12 Silliman RA, Demissie S, Troyan SL. The care of older women with early-stage breast cancer: what is the role of surgeon gender?Med Care 1999;37:1057-67. doi:10.1097/00005650-19991000000009

13 Hershman DL, Buono D, McBride RB, et al. Surgeon characteristics and receipt of adjuvant radiotherapy in women with breast cancer Natl Cancer Inst 2008;100:199-206. doi:10.1093/jnci/djm320

14 Arrington AK, Jarosek SL, Virnig BA, Habermann EB, Tuttle TM. Patient and surgeon characteristics associated with increased use of contralateral prophylactic mastectomy in patients with breast cancer. Ann Surg Oncol 2009;16:2697-704. doi:10.1245/s10434-009$0641-z$

15 Gilligan MA, Neuner I, Sparapani R, Laud PW, Nattinger AB. Surgeon characteristics and variations in treatment for earlystage breast cancer. Arch Surg 2007;142:17-22. doi:10.1001/ archsurg.142.1.17

16 Wallis C), Ravi B, Coburn N, Nam RK, Detsky AS, Satkunasivam R. Comparison of postoperative outcomes among patients treated by male and female surgeons: a population based matched cohort study. BMJ 2017:359:j4366. doi:10.1136/bmi.j4366

17 Moja L, Piatti A, Pecoraro V, et al. Timing matters in hip fracture surgery: patients operated within 48 hours have better outcomes. A meta-analysis and meta-regression of over 190,000 patients. PLoS One 2012;7:e46175. doi:10.1371/journal. pone.0046175

18 Sahni NR, Dalton M, Cutler DM, Birkmeyer JD, Chandra A. Surgeon specialization and operative mortality in United States: retrospective analysis. BMJ 2016;354:i3571. doi:10.1136/bmj.i3571

19 Shoda N, Yasunaga $\mathrm{H}$, Horiguchi $\mathrm{H}$, et al. Risk factors affecting inhospital mortality after hip fracture: retrospective analysis using the Japanese Diagnosis Procedure Combination Database. BMJ Open 2012;2:e000416. doi:10.1136/bmjopen-2011-000416

20 Birkmeyer JD, Stukel TA, Siewers AE, Goodney PP, Wennberg DE, Lucas FL. Surgeon volume and operative mortality in the United States. N Engl I Med 2003;349:2117-27. doi:10.1056/ NEJMsa035205

21 Finks JF, Osborne NH, Birkmeyer JD. Trends in hospital volume and operative mortality for high-risk surgery. N Engl J Med 2011;364:2128-37. doi:10.1056/NEJMsa1010705

22 Healthcare Cost and Utilization Project. Clinical Classifications Software (CCS) for ICD-9-CM. 2017. https://www.hcup-us.ahrq.gov/ toolssoftware/ccs/ccs.jsp.

23 Miller ME, Welch WP, Welch HG. The impact of practicing in multiple hospitals on physician profiles. Med Care 1996;34:455-62 doi:10.1097/00005650-199605000-00007

24 Jena AB, Khullar D, Ho O, Olenski AR, Blumenthal DM. Sex Differences in Academic Rank in US Medical Schools in 2014. JAMA 2015;314 1149-58. doi:10.1001/jama.2015.10680

25 Jena AB, Olenski AR, Blumenthal DM. Sex Differences in Physician Salary in US Public Medical Schools. JAMA Intern Med 2016;176:1294-304. doi:10.1001/jamainternmed.2016.3284

26 Tsugawa Y, Jena AB, Figueroa JF, Orav EJ, Blumenthal DM, Jha AK. Comparison of Hospital Mortality and Readmission Rates for Medicare Patients Treated by Male vs Female Physicians. JAMA Intern Med 2017;177:206-13. doi:10.1001/jamainternmed.2016.7875

27 Tsugawa Y, Jena AB, Orav EJ, Jha AK. Quality of care delivered by general internists in US hospitals who graduated from foreign versus US medical schools: observational study. BMJ 2017;356:j273. doi:10.1136/bmj.j273

28 Tsugawa Y, Jha AK, Newhouse JP, Zaslavsky AM, Jena AB. Variation in Physician Spending and Association With Patient Outcomes. JAMA Intern Med 2017;177:675-82. doi:10.1001/ jamainternmed.2017.0059

29 Reames BN, Ghaferi AA, Birkmeyer JD, Dimick JB. Hospital volume and operative mortality in the modern era. Ann Surg 2014;260:244-51. doi:10.1097/SLA.0000000000000375

30 Research Data Assistance Center. Death information in the research identifiable Medicare data. 2016.https://www.resdac.org/ resconnect/articles/117

31 Elixhauser A, Steiner C, Harris DR, Coffey RM. Comorbidity measures for use with administrative data. Med Care 1998:36:8-27. doi:10.1097/00005650-199801000-00004

32 Aylin P, Alexandrescu R, Jen MH, Mayer EK, Bottle A. Day of week of procedure and 30 day mortality for elective surgery: retrospective analysis of hospital episode statistics. BMJ 2013;346:f2424. doi:10.1136/bmj.f2424

33 Gillies MA, Lone NI, Pearse RM, et al. Effect of day of the week on short- and long-term mortality after emergency general surgery. $\mathrm{Br}$ J Surg 2017;104:936-45. doi:10.1002/bjs.10507 
34 Zare MM, Itani KM, Schifftner TL, Henderson WG, Khuri SF. Mortality after nonemergent major surgery performed on Friday versus Monday through Wednesday. Ann Surg 2007;246:866-74. doi:10.1097| SLA.0b013e3180cc2e60

35 Fitzmaurice GM, Laird NM, Ware JH. Applied longitudinal analysis. John Wiley \& Sons, 2012

36 Gardiner JC, Luo Z, Roman LA. Fixed effects, random effects and GEE: what are the differences?Stat Med 2009;28:221-39. doi:10.1002/ sim. 3478

37 Gunasekara Fl, Richardson K, Carter K, Blakely T. Fixed effects analysis of repeated measures data. Int J Epidemiol 2014;43:264-9. doi:10.1093/ije/dyt221

38 Williams R. Using the margins command to estimate and interpret adjusted predictions and marginal effects. Stata J 2012;12:308

39 Parzen M, Lipsitz SR, Ibrahim JG, Lipshultz S. A weighted estimating equation for linear regression with missing covariate data. Stat Med 2002;21:2421-36. doi:10.1002/sim.1195

40 Agency for Healthcare Research and Quality. HCUPnet. https:// hcupnet.ahrq.gov/\#setup.

41 Tsugawa Y, Newhouse JP, Zaslavsky AM, Blumenthal DM, Jena AB Physician age and outcomes in elderly patients in hospital in the US: observational study. BMJ 2017;357:j1797. doi:10.1136/bmj. j1797

42 Bell RH Jr, Biester TW, Tabuenca A, et al. Operative experience of residents in US general surgery programs: a gap between expectation and experience. Ann Surg 2009;249:719-24. doi:10.1097/ SLA.0b013e3181a38e59

43 Condren AB, Divino CM. Effect of 2011 Accreditation Council for Graduate Medical Education Duty-Hour Regulations on Objective Measures of Surgical Training. J Surg Educ 2015;72:855-61. doi:10.1016/j.jsurg.2015.04.018

44 Bilimoria KY, Chung JW, Hedges LV, et al. National ClusterRandomized Trial of Duty-Hour Flexibility in Surgical Training. N Engl J Med 2016;374:713-27. doi:10.1056/NEJMoa1515724

45 Ly DP, Seabury SA, Jena AB. Differences in incomes of physicians in the United States by race and sex: observational study. BMJ 2016;353:i2923. doi:10.1136/bmj.i2923
46 Capek L, Edwards DE, Mackinnon SE. Plastic surgeons: a gender comparison. Plast Reconstr Surg 1997;99:289-99. doi:10.1097/00006534-199702000-00001

47 Dresler CM, Padgett DL, MacKinnon SE, Patterson GA. Experiences of women in cardiothoracic surgery. A gender comparison. Arch Surg 1996;131:1128-34, discussion 1135. doi:10.1001/ archsurg.1996.01430230010002

48 Spencer ES, Deal AM, Pruthi NR, et al. Gender Differences in Compensation, Job Satisfaction and Other Practice Patterns in Urology. J Urol 2016;195:450-5. doi:10.1016/j.juro.2015.08.100

49 Epstein NE. Discrimination against female surgeons is still alive: Where are the full professorships and chairs of departments? Surg Neurol Int 2017:8:93, doi:10.4103/sni.sni 90 17

50 Zhuge Y, Kaufman J, Simeone DM, Chen $\mathrm{H}$, Velazquez OC. Is there still a glass ceiling for women in academic surgery?Ann Surg 2011;253:637-43. doi:10.1097/SLA.0b013e3182111120

51 Duclos A, Peix JL, Colin C, et al, CATHY Study Group. Influence of experience on performance of individual surgeons in thyroid surgery: prospective cross sectional multicentre study. BMJ 2012;344:d8041. doi:10.1136/bmj.d8041

52 Neumayer LA, Gawande AA, Wang J, et al, CSP \#456 Investigators. Proficiency of surgeons in inguinal hernia repair: effect of experience and age. Ann Surg 2005;242:344-8, discussion 348-52.

53 Patel MS, Volpp KG, Small DS, et al. Association of the 2011 ACGME resident duty hour reforms with mortality and readmissions among hospitalized Medicare patients. JAMA 2014;312:2364-73. doi:10.1001/jama.2014.15273

54 Rajaram R, Chung JW, Jones AT, et al. Association of the 2011 ACGME resident duty hour reform with general surgery patient outcomes and with resident examination performance. JAMA 2014;312:2374-84. doi:10.1001/jama.2014.15277

55 Schneider JR, Coyle JJ, Ryan ER, Bell RH Jr, DaRosa DA. Implementation and evaluation of a new surgical residency model. J Am Coll Surg 2007;205:393-404. doi:10.1016/j. jamcollsurg.2007.05.013

\section{Supplementary tables and figures}

